九州大学学術情報リポジトリ

Kyushu University Institutional Repository

\title{
Accumulation of 8-0xo-2' -deoxyguanosine and increased expression of hMTH1 protein in brain tumors
}

\section{I ida, Takashi}

Department of Neuropathology, Neurological Institute, Graduate School of Medical Sciences I

Core Research for Evolutional Science and Technology, Japan Science and Technology Corporation

\section{Furuta, Akiko}

Department of Neuropathology, Neurological Institute, Graduate School of Medical Sciences I Core Research for Evolutional Science and Technology, Japan Science and Technology Corporation

Kawashima, Masatou

Department of Neuropathology, Neurological Institute, Graduate School of Medical Sciences

Nishida, Jun-ichi

Department of Biochemistry, Medical Institute of Bioregulation

他

http://hdl. handle. net/2324/5601

出版情報：Neuro-oncology. 3 (2)，pp.73-81，2001-04. Duke University Press バージョン：

権利関係 : ๑ 2001 Society for Neuro-Oncology 


\title{
Accumulation of 8-0xo-2'-deoxyguanosine and increased expression of hMTH1 protein in brain tumors
}

\author{
Takashi lida, ${ }^{1}$ Akiko Furuta, Masatou Kawashima, Jun-ichi Nishida, \\ Yusaku Nakabeppu, and Toru Iwaki \\ Department of Neuropathology, Neurological Institute, Graduate School of Medical Sciences \\ (T.Ii., A.F., M.K., T.IW.), Department of Biochemistry, Medical Institute of Bioregulation (J.N., Y.N.), \\ Kyushu University, Fukuoka, 812-8582, Japan; and Core Research for Evolutional Science and Technology, \\ Japan Science and Technology Corporation, Tokyo, 105-0011, Japan (T.Ii., A.F., Y.N., T.Iw.)
}

Oxidative DNA damage generated by an attack of reactive oxygen species causes mutation or cell death that may lead to various diseases and may be related to initiation or progression of carcinogenesis. 8-Oxo-2'deoxyguanosine (8-oxo-dG) is a major oxidative DNA damage product that can result in mutation, and hMTH1, human MutT homolog protein 1, has been identified as an enzyme that hydrolyzes 8-oxo-dGTP to the monophosphate, thus preventing accumulation of 8oxo-dG in DNA. With immunohistochemical approaches, we investigated accumulation of 8-oxo-dG and expression of hMTH1 in brain tumor tissues obtained from surgical and autopsy cases, including $\mathbf{4 2}$ neuroepithelial tumors, 5 meningiomas, 2 metastatic brain tumors, and 1 schwannoma. 8-Oxo-dG accumulation and hMTH1 expression were increased in various brain tumors. Nuclei of brain tumor cells were immunoreactive for 8-oxo-dG in all cases. In most cases, both nuclei and cytoplasm of the tumor cells were immunoreactive for hMTH1. Both 8-oxo-dG accumula-

Received 19 October 2000, accepted 20 December 2000

${ }^{1}$ Address correspondence and reprint requests to Dr. Takashi lida, Department of Neuropathology, Neurological Institute, Graduate School of Medical Sciences, Kyushu University 60, Fukuoka, 812-8582, Japan.

\footnotetext{
${ }^{2}$ Abbreviations used are as follows: 8-oxo-dG, 8-oxo-2'deoxyguanosine; 8-oxo-dGTP, 8-oxo-2'-deoxyguanosine-5'triphosphate; hMTH1, human MutT homolog protein 1; OD, optical density; rOD, relative optical density; ROS, reactive oxygen species; TBST, $25 \mathrm{mM}$ Tris- $\mathrm{HCl}, \mathrm{pH} 7.6,0.15 \mathrm{M} \mathrm{NaCl}, 0.05 \%$ Tween 20, $0.05 \% \mathrm{NaN}_{3}$.
}

tion and hMTH1 expression were most evident in highgrade gliomas, indicating that oxidative stress was high in these gliomas. Thus, the defense mechanism against such oxidative stress may be enhanced as well. These results suggest that oxidative stress may play a role in tumor progression. Neuro-Oncology 3, 73-81, 2001 (Posted to Neuro-Oncology [serial online], Doc. 00-058, February 20, 2001. URL <neuro-oncology.mc.duke.edu>)

$\mathrm{R}$ $\mathrm{OS}^{2}$ are continuously arising in normal cellular metabolism, where they oxidize proteins, lipids, and nucleic acids (Fraga et al., 1990). There are various protective mechanisms against such oxidative damage. When the balance between ROS generation and protective mechanisms is lost, oxidative stress is increased and cells are highly damaged. Oxidative DNA damage generated by ROS results in mutations that may cause various diseases, including cancer (Lee et al., 1998; Musarrat et al., 1996).

8-Oxoguanine, an oxidized form of guanine, is a well-known marker of oxidative DNA damage, and it causes A:T to C:G or G:C to T:A transversion mutations because of its base pairing nature with adenine as well as cytosine (Maki and Sekiguchi, 1992). It has been reported that 8-oxo-dG accumulates at higher levels in breast, renal cell, and gastric tumors than in adjacent or normal tissues (Lee et al., 1998; Musarrat et al., 1996; Okamoto et al., 1994), indicating that there is increased oxidative stress in tumor tissues, and it may be related to initiation or progression of carcinogenesis.

To minimize such deleterious effects of oxidative DNA damage, organisms come equipped with elaborate error-avoiding mechanisms. In Escherichia coli, there are 
3 enzymes, MutM, MutY, and MutT, that are involved in avoiding errors in DNA caused by 8-oxoguanine (Maki and Sekiguchi, 1992; Michaels et al., 1992; Tchou et al., 1991). MutM protein removes 8-oxoguanine paired with cytosine (Tchou et al., 1991), and MutY protein removes adenine paired with 8-oxoguanine in DNA (Michaels et al., 1992). MutT protein hydrolyzes 8-oxo-dGTP to the corresponding monophosphate, thereby preventing misincorporation of 8-oxo-dG into DNA (Akiyama et al., 1989; Maki and Sekiguchi, 1992; Sekiguchi, 1996). Human cells possess the OGG1, MYH, and MTH1 genes, which are the human homologs of the E. coli genes mutM (Boiteux and Radicella, 1999; Nishioka et al., 1999), mutY, (Ohtsubo et al., 2000; Slupska et al., 1996; 1999), and mutT, respectively (Furuichi et al., 1994; Sakumi et al., 1993).

Human MTH1 (hMTH1) protein hydrolyzes oxidized purine-nucleoside triphosphates, including not only 8-oxo-dGTP but also 2-hydroxy-dATP (Fujikawa et al., 1999; Sakumi et al., 1993), indicating that there are various other routes of oxidative DNA damage that are also deleterious for cells. Correlation between hMTH1 expression and clinical stage has previously been discussed with regard to breast and renal cell carcinoma (Okamoto et al., 1996; Wani et al., 1998). Furthermore, it has been suggested that hMTH1 might be a useful marker of oxidative stress and can be used to explore the relationship between oxidative stress and genomic instability (Kennedy et al., 1998).

Accumulation of 8-oxo-dG in various tumors has been examined with immunohistochemical approaches (Kondo et al., 1999; Matsui et al., 1999). In brain tumor tissues, expression of superoxide dismutase and nitric oxide synthase, which may increase oxidative stress, has been examined (Cobbs et al., 1995; Yoshii et al., 1999), but there is no report on 8 -oxo-dG accumulation and hMTH1 expression. In the present study, we used immunohistochemistry to examine levels of 8 -oxo-dG accumulation and hMTH1 expression in brain tumor tissues and to evaluate the patterns of their occurrence in low- and high-grade tumors.

\section{Materials and Methods}

Cases

Tumor tissues were obtained at surgery from 45 patients (27 men and 18 women, ranging in age from 1 to 76 years) (Table 1 , cases $1-45$ ). We also investigated 5 additional brain tumors obtained by postmortem examination (1 glioblastoma, 1 anaplastic ependymoma, 1 medulloblastoma, and 2 metastatic brain tumors) together with normal brain tissues (Table 1, cases 46-50). As controls, 5 samples ( 3 men and 2 women, ranging in age from 47 to 79 years) of cerebral cortex without neurologic disorder were used.

\section{Antibodies}

Rabbit polyclonal antibodies against hMTH1 protein (anti-MTH1) were raised by immunizing the recombi- nant hMTH1d protein and were affinity-purified with the aid of antigen columns, as previously described (Kang et al., 1995; Kakuma et al., 1995). A monoclonal antibody specific for 8-oxo-dG (anti-8-oxo-dG), N45.1, was obtained from Nippon Roukaseigyo Kenkyujo (Shizuoka, Japan). The specificity of N45.1 was confirmed in previous studies (Toyokuni et al., 1997).

\section{Sodium Dodecyl Sulfate-Polyacrylamide Gel Eletrophoresis and Immunoblotting for hMTH1}

Frozen tumor samples of an oligodendroglioma (Table 1, case 28), an anaplastic ependymoma (Table 1, case 30), and a glioblastoma and its adjacent normal tissue (Table 1 , case 8 ) were individually homogenized in protein lysis buffer in $20 \mathrm{mM}$ Tris- $\mathrm{HCl}(\mathrm{pH} 7.4)$ containing $10 \%$ sucrose and protease inhibitors (protease inhibitor cocktail, Complete Mini; Boehringer Mannheim, Mannheim, Germany). The protein concentrations were determined by a Coomassie Plus Protein Assay Reagent (Pierce, Rockford, Ill.), with bovine serum albumin as the standard. Laemmli's sample buffer was added to this mixture. Each protein sample $(20 \mu \mathrm{g} / \mathrm{lane})$ and recombinant hMTH1d (Yakushiji et al., 1997) was separated by $12 \%$ sodium dodecyl sulfate-polyacrylamide gel eletrophoresis and transferred onto a polyvinylidene difluoride membrane (PVDF; Millipore, Bedford, MA). After the reaction was blocked with $5 \%$ low-fat milk in TBST, the membrane was incubated with anti-MTH1 (Kang et al., 1995; Kakuma et al., 1995) in TBST containing 5\% lowfat milk at $4^{\circ} \mathrm{C}$ overnight. The membrane was then washed in TBST and incubated with alkaline phosphatase-conjugated antirabbit IgG antibody $(1: 7500$ dilution, Promega, Madison, Wis.) in TBST containing $5 \%$ low-fat milk for $30 \mathrm{~min}$. After the membrane was washed in TBST, the signal was visualized with CDP-Star detection reagent (Amersham, Little Chalfont, U.K.) according to the manufacturer's instruction.

\section{Immunohistochemistry}

Immunohistochemistry with N45.1 for 8-oxo-dG (1:100 dilution) or with anti-MTH1 $(0.5 \mu \mathrm{g} / \mathrm{ml})$ was performed on paraffin sections by the indirect immunoperoxidase method. Specimens were fixed in 10\% formalin and embedded in paraffin; samples were then sectioned at $5 \mu \mathrm{m}$. Sections were deparaffinized in xylene and hydrated in an ethanol gradient. Endogenous peroxidase activity was blocked with $0.3 \% \quad \mathrm{H}_{2} \mathrm{O}_{2}$ in absolute methanol for $30 \mathrm{~min}$ at room temperature. After being rinsed in tap water, sections were completely immersed in citrate buffer and autoclaved for 10 min for immunohistochemical analysis of hMTH1. Sections were then washed in $50 \mathrm{mM}$ Tris- $\mathrm{HCl}(\mathrm{pH} \mathrm{7.6)}$, followed by overnight incubation with the primary antibodies at $4^{\circ} \mathrm{C}$. After being washed again in the same buffer, sections were incubated with horseradish peroxidase-conjugated secondary antibody (1:200 dilution, Vector Laboratories, Burlingame, Calif.). The colored reaction product was developed with 3,3'-diaminobenzidine tetrahydrochloride $(\mathrm{DAB})$ solution. Immunohistochemical procedures were performed in the same condition. 
Table 1. Immunohistochemical results of intensity level and intracellular localization of 8-oxo-dG and hMTH in brain tumors

\begin{tabular}{|c|c|c|c|c|c|c|c|c|c|}
\hline \multirow[b]{3}{*}{ Case No. } & \multirow[b]{3}{*}{ Diagnosis } & \multirow[b]{3}{*}{ Age } & \multirow[b]{3}{*}{ Sex } & \multicolumn{3}{|c|}{ 8-Oxo-dG immunoreactivity } & \multicolumn{3}{|c|}{ hMTH1 immunoreactivity } \\
\hline & & & & \multirow[b]{2}{*}{$\begin{array}{l}\text { Intensity } \\
\text { level }^{\mathrm{a}}\end{array}$} & \multicolumn{2}{|c|}{$\begin{array}{l}\text { Intracellular } \\
\text { localization }\end{array}$} & \multirow[b]{2}{*}{$\begin{array}{l}\text { Intensity } \\
\text { level }^{\mathrm{a}}\end{array}$} & \multicolumn{2}{|c|}{$\begin{array}{l}\text { Intracellular } \\
\text { localization }\end{array}$} \\
\hline & & & & & Nucleus & Cytoplasm & & Nucleus & Cytoplasm \\
\hline \multicolumn{10}{|c|}{ Surgical cases } \\
\hline 1 & Glioblastoma & 69 & $M$ & 3 & + & - & 3 & + & + \\
\hline 2 & Glioblastoma & 66 & $M$ & 3 & + & - & 2 & + & + \\
\hline 3 & Glioblastoma & 41 & $\mathrm{~F}$ & 3 & + & - & 2 & + & + \\
\hline 4 & Glioblastoma & 60 & $M$ & 3 & + & + & 2 & + & + \\
\hline 5 & Glioblastoma & 63 & $\mathrm{~F}$ & 3 & + & + & 2 & + & + \\
\hline 6 & Glioblastoma & 44 & $\mathrm{~F}$ & 2 & + & - & 1 & + & + \\
\hline 7 & Glioblastoma & 68 & $\mathrm{~F}$ & 2 & + & - & 3 & + & + \\
\hline 8 & Glioblastoma & 42 & $M$ & 2 & + & - & 2 & + & + \\
\hline 9 & Anaplastic astrocytoma & 72 & $M$ & 2 & + & - & 1 & - & + \\
\hline 10 & Anaplastic astrocytoma & 16 & $M$ & 2 & + & - & 2 & + & + \\
\hline 11 & Anaplastic astrocytoma & 76 & $M$ & 3 & + & + & 2 & + & + \\
\hline 12 & Anaplastic astrocytoma & 15 & $M$ & 3 & + & - & 2 & + & + \\
\hline 13 & Anaplastic astrocytoma & 60 & $M$ & 3 & + & - & 2 & + & + \\
\hline 14 & Anaplastic astrocytoma & 37 & $M$ & 3 & + & - & 3 & + & + \\
\hline 15 & Anaplastic astrocytoma & 52 & $\mathrm{~F}$ & 3 & + & - & 2 & + & + \\
\hline 16 & Anaplastic astrocytoma & 56 & $M$ & 3 & + & - & 3 & + & + \\
\hline 17 & Astrocytoma & 9 & $\mathrm{~F}$ & 2 & + & - & 2 & + & + \\
\hline 18 & Astrocytoma & 25 & $M$ & 2 & + & - & 2 & + & + \\
\hline 19 & Fibrillary astrocytoma & 43 & $\mathrm{~F}$ & 1 & + & - & 1 & - & + \\
\hline 20 & Fibrillary astrocytoma & 63 & $\mathrm{~F}$ & 3 & + & - & 2 & - & + \\
\hline 21 & Fibrillary astrocytoma & 28 & $M$ & 1 & + & - & 1 & - & + \\
\hline 22 & Pilocytic astrocytoma & 1 & $M$ & 1 & + & - & 1 & - & + \\
\hline 23 & Anaplastic oligodendroglioma & 60 & $\mathrm{~F}$ & 3 & + & - & 3 & + & + \\
\hline 24 & Anaplastic oligodendroglioma & 54 & $M$ & 2 & + & - & 3 & + & + \\
\hline 25 & Oligoastrocytoma & 27 & $M$ & 2 & + & - & 1 & + & + \\
\hline 26 & Oligoastrocytoma & 13 & $M$ & 2 & + & - & 1 & - & + \\
\hline 27 & Oligoastrocytoma & 45 & $M$ & 1 & + & - & 1 & + & + \\
\hline 28 & Oligodendroglioma & 49 & $M$ & 2 & + & - & 2 & + & + \\
\hline 29 & Oligodendroglioma & 70 & $\mathrm{~F}$ & 2 & + & - & 2 & + & + \\
\hline 30 & Anaplastic ependymoma & 1 & $\mathrm{~F}$ & 2 & + & - & 2 & + & + \\
\hline 31 & Ependymoma & 12 & $M$ & 2 & + & - & 1 & - & + \\
\hline 32 & Subependymoma & 27 & $\mathrm{~F}$ & 1 & + & - & 1 & + & + \\
\hline 33 & Ganglioglioma & 9 & $\mathrm{~F}$ & 1 & + & - & 1 & - & + \\
\hline 34 & Medulloblastoma & 42 & $M$ & 3 & + & - & 2 & + & + \\
\hline 35 & Medulloblastoma & 4 & $M$ & 3 & + & - & 2 & + & + \\
\hline 36 & Medulloblastoma & 4 & $\mathrm{~F}$ & 2 & + & - & 3 & + & + \\
\hline 37 & Medulloblastoma & 11 & $M$ & 3 & + & - & 2 & + & + \\
\hline 38 & Neuroblastoma & 1 & $M$ & 3 & + & - & 2 & + & + \\
\hline 39 & Central neurocytoma & 42 & $M$ & 2 & + & - & 1 & - & + \\
\hline 40 & Schwannoma & 55 & $\mathrm{~F}$ & 1 & + & - & 1 & + & + \\
\hline 41 & Meningioma & 47 & $M$ & 2 & + & - & 2 & + & + \\
\hline 42 & Meningioma & 64 & $M$ & 2 & + & - & 2 & + & + \\
\hline 43 & Meningioma & 60 & $\mathrm{~F}$ & 2 & + & - & 1 & + & + \\
\hline 44 & Meningioma & 53 & $\mathrm{~F}$ & 1 & + & - & 1 & + & + \\
\hline 45 & Meningioma & 37 & $\mathrm{~F}$ & 1 & + & - & 1 & + & + \\
\hline \multicolumn{10}{|c|}{ Autopsy cases } \\
\hline 46 & Glioblastoma & 65 & $M$ & $2(1)$ & + & + & $3(1)$ & + & + \\
\hline 47 & Anaplastic ependymoma & 37 & $M$ & $2(2)$ & + & - & $2(2)$ & + & + \\
\hline 48 & Medulloblastoma & 8 & $M$ & $2(1)$ & + & - & $3(1)$ & + & + \\
\hline 49 & Metastatic carcinoma & 34 & $\mathrm{~F}$ & $2(1)$ & + & - & $3(1)$ & + & + \\
\hline 50 & Metastatic carcinoma & 76 & $\mathrm{~F}$ & $2(1)$ & + & - & $2(0)$ & + & + \\
\hline
\end{tabular}

Abbreviations: $M$, male; F, female.

antensity levels of immunoreactivity were 0 , not detectable; 1 , faint; 2 , moderate; or 3, high, according to the relative optical density. Numbers in parentheses indicate intensity level in normal tissue from the same specimen. 


\section{Evaluation and Semiquantitative Analysis}

Intensity levels of immunoreactivity were scored as follows. The OD of the 8-oxo-G and hMTH1 immunoreactions was measured for surgically removed tissues with National Institutes of Health image software version 1.6. Four separate fields of each specimen were selected, and the OD was obtained for each field. The ODs of each case were averaged, and the rOD was obtained individually by dividing the averaged OD of a case by the maximum OD among all cases. According to the $\mathrm{rOD}$, intensity levels of immunoreactivity were categorized as $(0)$ not detectable; (1) faint $(0<\mathrm{rOD}=$ $0.3)$; (2) moderate $(0.3<\mathrm{rOD}=0.7)$; and ( 3$)$ high $(0.7$ $<\mathrm{rOD}=1$ ).

The OD of the 8-oxo-G and hMTH1 immunoreactions was also measured for autopsied tissues. Both tumor and normal cerebral cortex were selected for each case and their ODs were measured in the following manner. Four separate fields were selected and the OD was obtained for each of the 4 fields. The ODs were averaged after being corrected for background by subtracting the OD of the cerebral white matter on the same section. Statistical analysis of the difference in corrected OD value between tumor and cerebral cortex was performed using the StatView-J4.5 program (Abacus Concepts, Berkeley, Calif.) and the Wilcoxon signed-rank test. $P<0.05$ was considered significant.

Intensity levels of immunoreactivity between highgrade and low-grade glioma were tested for statistical significance using the Mann-Whitney $U$ test. $P<0.05$ was considered significant.

\section{Results}

\section{bMTH1 Immunoblot Analysis}

The result of immunoblotting with anti-MTH1 is shown in Fig. 1. Tissue homogenates from anaplastic ependymoma, oligodendroglioma, and glioblastoma contained hMTH1 protein detected as a distinct band migrating at $18 \mathrm{kDa}$, identical to recombinant hMTH1. Normal tissue homogenates did not contain a detectable level of hMTH1.

\section{Immunohistochemistry for 8-Oxo-dG and hMTH1}

Control cases. In 4 of 5 control cases, cerebral cortex showed faint immunoreactivity to both anti-8-oxo-dG and anti-MTH1. One case showed negative immunoreactivity to anti-8-oxo-dG and anti-MTH1.

Brain tumors from surgical cases. As summarized in Table 1, nuclei of many tumor cells were immunoreactive to anti-8-oxo-dG in all 45 cases (Fig. 2A, 2C, 2E, and 2G). Similarly, most of the tumor cells showed immunoreactivity to anti-MTH1 in all 45 cases. In 36 of 45 cases, both nuclei and cytoplasm were stained by anti-MTH1 (Fig. 2D, 2F, and 2H), and in the other 9, only the cytoplasm was immunoreactive (Fig. 2B). The vascular wall within the tumor tissues showed negative or faint immunoreactivity to both anti-8-oxo-dG and anti-MTH1 (Fig. 2C and 2D).
In cases of high-grade glioma, including glioblastoma (Fig. 2E), anaplastic astrocytoma (Fig. 2C), anaplastic ependymoma, and anaplastic oligodendroglioma, 12 of 19 cases showed high anti-8-oxo-dG immunoreactivity. Seven of these 19 showed moderate immunoreactivity to anti-8-oxo-dG. In low-grade glioma, including astrocytoma, pilocytic astrocytoma, fibrillary astrocytoma, oligoastrocytoma (Fig. 2A), oligodendroglioma, subependymoma, ependymoma, and ganglioglioma, 6 of 14 showed faint, and 7 of 14 cases showed moderate immunoreactivity to the antibody.

In 6 of 19 cases of high-grade glioma, the tumors showed high immunoreactivity to anti-MTH1. Eleven of these 19 cases showed moderate immunoreactivity to anti-MTH1. In low-grade glioma, 9 of 14 cases showed faint immunoreactivity to the antibodies. The other 5 showed moderate immunoreactivity, and no case showed high immunoreactivity to anti-MTH1. Thus, high-grade glioma showed more increased immunoreactivities to both anti-8-oxo-dG and anti-MTH1, compared with those of low-grade glioma (Fig. 3A and 3B). Statistical analyses revealed significant differences in immunoreactivities to both anti-8-oxo-dG and anti-MTH1 between high-grade and low-grade glioma $(P<0.05)$.

In 4 cases of medulloblastoma, all showed moderate or high immunoreactivities to both anti-8-oxo-dG and anti-MTH1 (Fig. 2G and 2H).

Brain tumor from autopsy. As summarized in Table 1, in 4 of 5 cases, brain tumor tissues were more intensively stained for both anti-8-oxo-dG and anti-MTH1 than were normal tissues in the same specimen (Fig. 4A and 4B). Statistical analyses revealed a significant increase in immunoreactivities for both anti-8-oxo-dG and antiMTH1 in the tumors compared with those in the cerebral cortex (Table $2, P<0.05$ ).

\section{Discussion}

It is generally accepted that ROS are involved in early events of carcinogenesis by causing premutagenic modi-

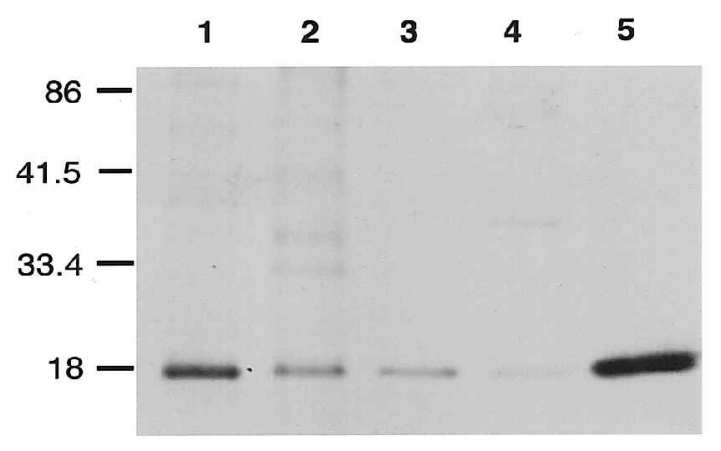

Fig.1. An immunoblot probed with anti-MTH1 antibody. Lane 1, anaplastic ependymoma; lane 2, oligodendroglioma; lane 3, glioblastoma; lane 4, normal tissue adjacent to glioblastoma; lane 5, recombinant hMTH1d. Lanes 1 to 3 showed a distinct band at $18 \mathrm{kDa}$ identical to the molecular weight of hMTH1d. Each sample loaded was $20 \mu \mathrm{g}$ of protein. The markers for molecular mass (Bio-Rad) are shown on the left. 


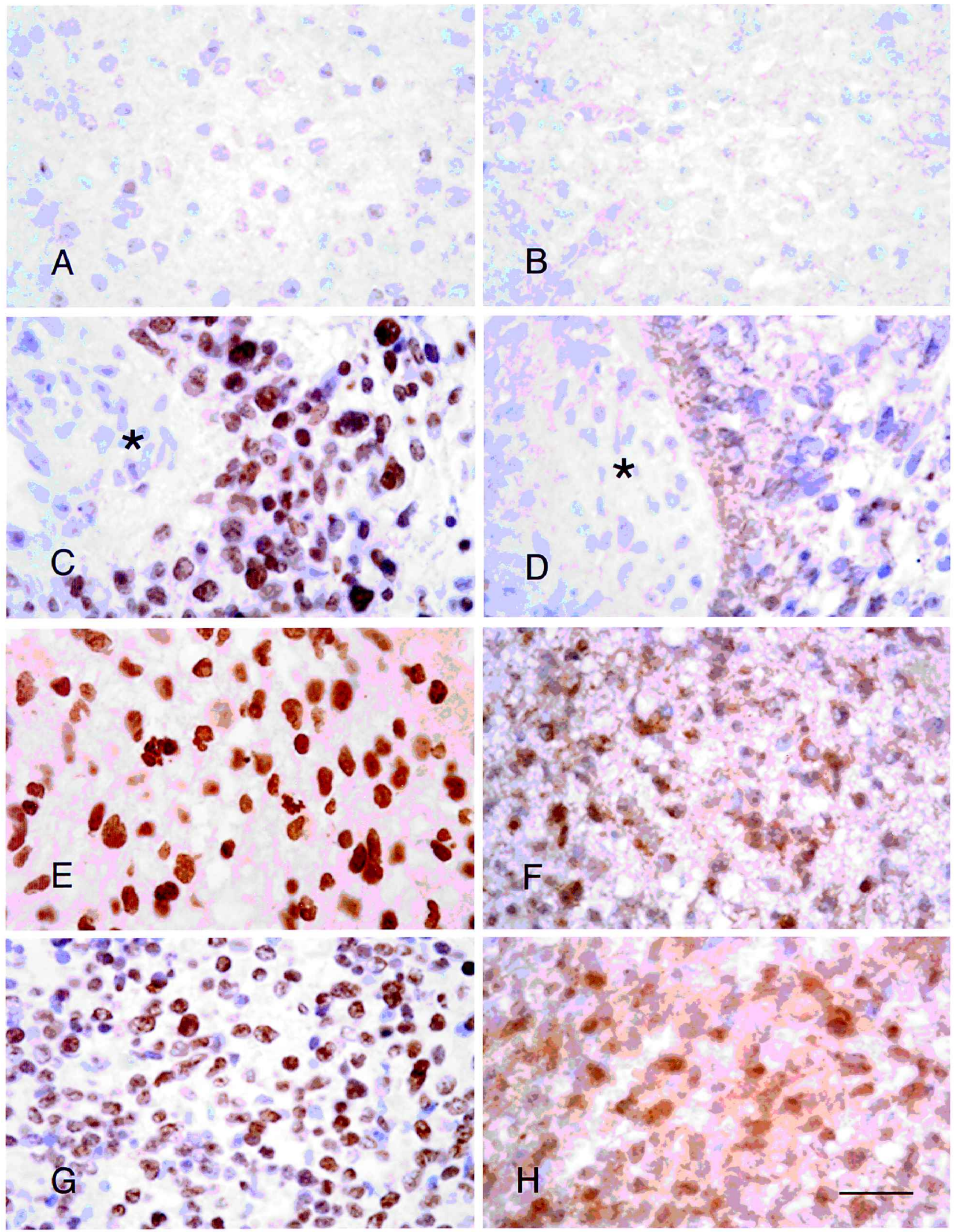

Fig. 2. Immunostaining of anti-8-oxo-dG $(A, C, E, G)$ and $h M T H 1(B, D, F, H)$ by hematoxylin counterstain in brain tumors from surgical cases. $A$ and B. Oligoastrocytoma. $C$ and D. Anaplastic astrocytoma. E and F. Glioblastoma. $G$ and H. Medulloblastoma. A and B show faint immunoreactivity in nuclei for 8-oxo-dG and in cytoplasm for hMTH1. C, E, and G show moderate (G) and high (C and E) immunoreactivity in nuclei for 8-oxo-dG. D, F, and $\mathrm{H}$ show moderate (D) and high ( $F$ and $H$ ) immunoreactivity in nuclei and cytoplasm for hMTH1. C and D show higher immunoreactivity in tumor cells than in vascular wall (asterisks). Bar represents $25 \mu \mathrm{m}$. 
A

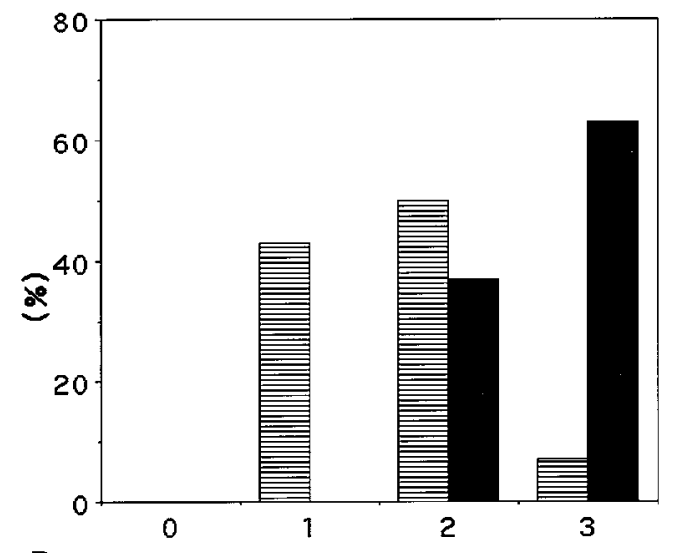

B

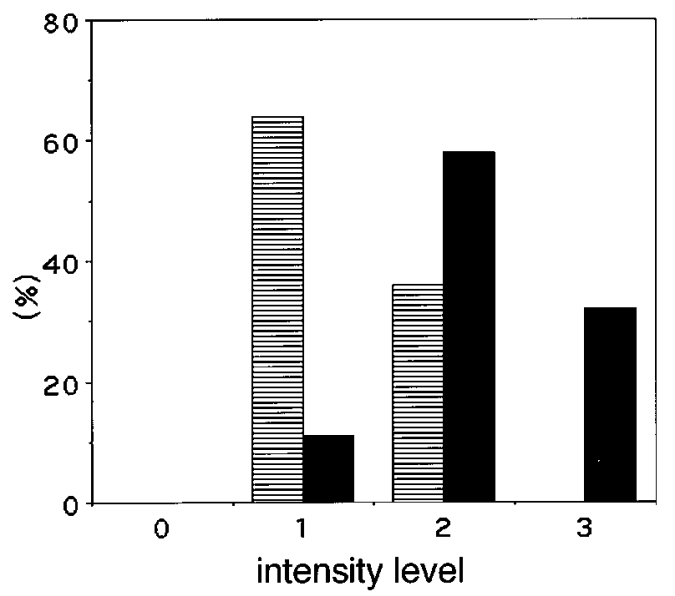

目 low grade glioma $(n=14)$

high grade glioma $(n=19)$

Fig. 3. Classification according to the intensity levels of 8-oxo-dG immunoreactivity (A) and hMTH1 immunoreactivity (B).

fications in DNA and accumulation of 8-oxoguanine, which indicates the presence of oxidative stress. Oxidative DNA damage is important, not only in initiation of carcinogenesis, but also in its progression (Toyokuni et al., 1997).

The main conclusion of the present study is that brain tumor tissues are exposed to severe oxidative stress, revealed by the presence of anti-8-oxo-dG when immunohistochemistry was used, and increase the capacity of defense mechanisms against such oxidative stress, revealed by MTH1-immunoreactivity. Furthermore, it is suggested that the grade of brain tumor is well correlated with the degree of oxidative stress. These results are an additional indication that oxidative stress may play a role in tumor progression.

Among the oxidative lesions of DNA, 8-oxoguanine, an oxidized form of guanine, is considered a major cause of mutagenesis by ROS (Tajiri et al., 1995; Boiteux and Radicella, 1999). Previous studies have shown that the levels of 8-oxo-dG in DNA are elevated in tumor cells (Lee et al., 1998; Musarrat et al., 1996; Oliva et al., 1997; Toyokuni et al., 1997; Wani et al., 1998; Yamamoto et al., 1996) and that 8-oxo-dG is accumu-
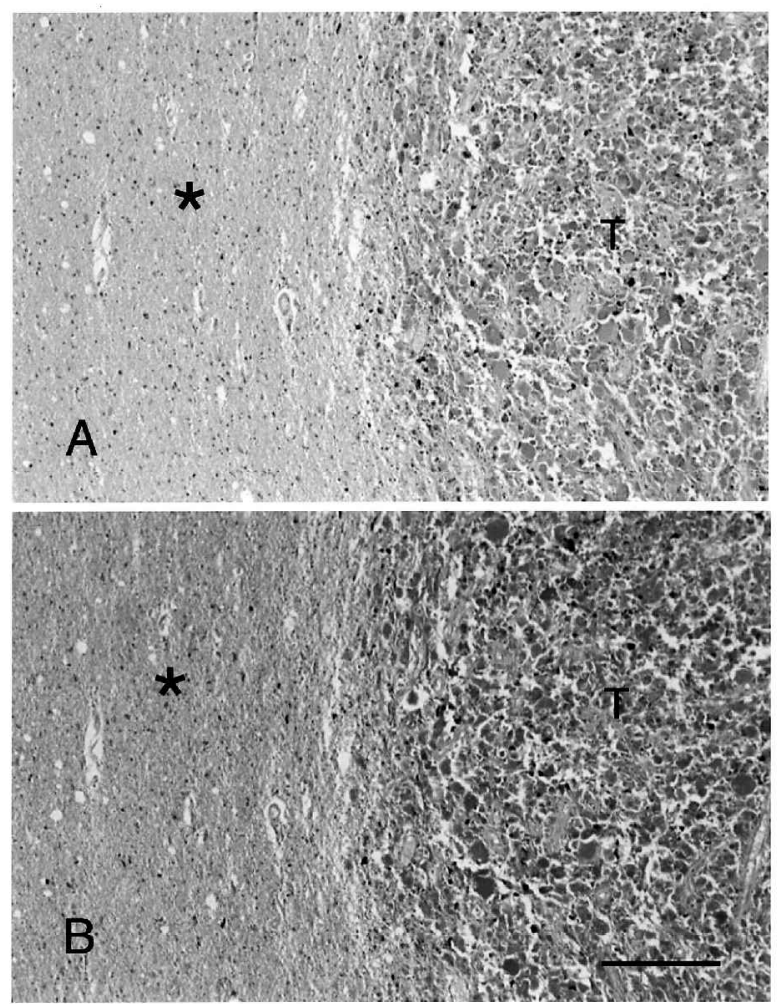

Fig. 4. Immunostaining of anti-8-oxo-dG (A) and hMTH1 (B) by hematoxylin counterstain in glioblastoma from an autopsy case. The tumor ( $\mathrm{T}$ ) is more intensively stained for 8-oxo-dG and $\mathrm{hMTH} 1$ than is the normal adjacent tissue (asterisks) in the same specimen. Bar represents $200 \mu \mathrm{m}$.

lated in their nuclei (Inoue et al., 1998; Kondo et al., 1999; Matsui et al., 1999). High accumulations of 8oxo-dG in DNA may play a causative role in carcinogenesis (Boiteux and Radicella, 1999; Floyd, 1990; Toyokuni et al., 1995).

In brain tumors, increased accumulation of 8-oxo-dG, based on data obtained by high-performance liquid chromatography with electrochemical detector (Nowak et al., 1999) and gas chromatography with mass spectrometry (Olinski et al., 1992), has been reported. Detecting the presence of 8-oxo-dG in preparations of tumor DNA is possibly affected by oxidation during the extraction from frozen materials. Our preliminary study showed that 8oxo-dG did not accumulate significantly in the paraffinembedded materials, whereas it was markedly increased in the specimens fixed for a longer time with $10 \%$ formalin solution. Therefore, direct investigation of paraffin sections with a short fixation time leads to more reliable study of 8-oxo-dG. In the present study, we examined the presence of 8 -oxo-dG in brain tumor tissues immunohistochemically and confirmed that 8-oxo-dG is indeed accumulated in brain tumor cells, especially in their nuclei. Our results indicate that brain tumor tissues are exposed to severe oxidative stress that mostly affects nuclear DNA.

MTH1 is an enzyme that hydrolyzes oxidized purine nucleoside triphosphates, such as 8-oxo-dGTP and 2hydroxy-dATP in the nucleotide pool, thereby reducing 
Table 2. Comparison of immunoreactivity between tumor and cerebral cortex

\begin{tabular}{lcc} 
& Tumor & Cerebral cortex \\
\hline 8-Oxo-dG & $24 \pm 8.3$ & $5.9 \pm 4.4$ \\
hMTH1 & $12.7 \pm 5.2$ & $5.6 \pm 1.5$ \\
\hline
\end{tabular}

Values are mean $\pm \mathrm{SD} . P<0.05$

accumulation of such oxidized nucleotides in DNA (Fujikawa et al., 1999; Sakumi et al., 1993; Sekiguchi, 1996). Recently, several studies revealed that the level of MTH1 mRNA is greatly increased in cancerous tissues, such as lung, renal cell, and breast tumors, compared with the adjacent normal tissues (Kennedy et al., 1998; Okamoto et al., 1996; Wani et al., 1998). The human MTH1 gene encodes 7 different mRNAs formed by alternative initiation and splicing, and 4 different isoforms of MTH1 polypeptides (MTH1a to MTH1d) were identified in cultured human cells (Oda et al., 1997; 1999). Thus, it is very important to address which isoform of MTH1 polypeptides is highly expressed in human cancerous tissues.

We have previously prepared anti-MTH1 antibodies that can be applied for detection of MTH1 protein on immunoblots and by immunohistochemistry as well (Kang et al., 1995; Kakuma et al., 1995). Using this antiMTH1, it was recently reported that expression of MTH1d, a major isoform of MTH1 polypeptides, is highly overexpressed in dopaminergic neurons of the sabstantia nigra in brain tissues derived from Parkinson's disease patients (Shimura-Miura et al., 1999), suggesting that MTH1d expression is enhanced by the increased oxidative stress known to affect dopaminergic neurons in patients with Parkinson's.

In the present study, using anti-MTH1 in an immunoblotting analysis, we detected an overexpressed $18-\mathrm{kDa}$ MTH1 polypeptide corresponding to the major isoform, MTH1d, in brain tumor tissues. Immunohistochemistry with the anti-MTH1 indicated that MTH1 protein was present in both nuclei and cytoplasm in 36 of 45 cases, and only in cytoplasm in 9 cases. In cultured human cells, MTH1d is present mainly in cytoplasm and some are present in mitochondria and nuclei (Kang et al., 1995). Because the pool of dNTP for nuclear DNA replication is present mainly in the cytosol in human cells (Bestwick et al., 1982), it seems likely that the MTH1 present in cytoplasm hydrolyzes 8-oxo-dGTP or 2-hydroxy-dATP generated in the nucleotide pool to prevent their misincorporation into DNA. Hence, increased accumulation of 8-oxo-dG in the nuclei of brain tumor cells indicates that there is a significantly higher level of oxidation of such nucleotides in the dNTP pool than in the adjacent normal tissues $(P<0.05)$. It is likely that the levels of oxidized nucleotides in the pool of tumor cells are beyond the hydrolyzing capacity of MTH1; thus, 8-oxo-dG was incorporated into nuclear DNA.

In tumor cells, increased oxidative stress may lead to accumulation of oxidized purine nucleoside triphosphates in the dNTP pool, which may trigger the enhanced expression of MTH1 and/or its translocation into nuclei.
Recently, Tanaka et al. (2000) identified a novel ribonucleotide reductase small subunit (p53R2), the expression of which is induced by $\mathrm{p} 53$. They hypothesized that p53R2 is likely to supply urgent precursors for DNA synthesis at the actual site of DNA repair within the damaged nuclei of arrested cells, because p53R2 translocates into nuclei after exposure of cells to DNA-damaging agents. It has been shown that a major classical ribonucleoside reductase complex locates mostly in cytoplasm and functions to supply precursors for replicative DNA synthesis. So the nuclear form of MTH1 may function to eliminate oxidized purine nucleotides from the precursor pool produced by p53R 2 complex for repair replication, because there is severe oxidative stress resulting in an increase of 8-oxo-dG accumulation in tumor cells.

Okamoto et al. (1996) suggested that the levels of MTH1 mRNA increase with the stage of disease. In contrast, Wani et al. (1998) found no significant association between MTH1 gene expression, tumor grade, and metastatic malignancy of breast tumors. Other studies found no correlation between clinical stage of cancer and 8-oxo-dG accumulation (Kondo et al., 1999; Okamoto et al., 1994). On the other hand, 2 groups reported that levels of 8-oxo-dG in malignant tumors were different from those of benign tumors (Kondo et al., 1999; Musarrat et al., 1996).

In the present study, we demonstrate that high-grade gliomas accumulate more 8 -oxo-dG and express more MTH1 than do low-grade gliomas. Brain tumor samples ranged from benign to malignant tumors. Although we cannot show a highly quantitative correlation to clinical stages of malignant tumors, a significant qualitative difference between high- and low-grade gliomas was demonstrated $(P<0.05)$. This result suggests that an increase in oxidative stress induces the corresponding defensive mechanisms, producing higher levels of defensive mechanisms against 8-oxo-dG accumulation in highgrade gliomas than in low-grade gliomas, as previously suggested by Kennedy et al. (1998). In addition, 18 of 19 high-grade gliomas showed hMTH1 expression in nuclei, whereas only 7 of 14 low-grade gliomas showed hMTH1 expression in nuclei. This result may also be related to tumor malignancy. Because few studies about hMTH1 expression in neoplasia have been reported, further studies are recommended to know its significance. Mutation of the TP53 gene is another factor that may alter cellular response to oxidative stress. However, what causes such increased oxidative stress in malignant cancer cells remains to be answered.

In medulloblastoma, as well as in high-grade glioma, all cases showed a moderate or high level of both 8-oxo$\mathrm{dG}$ accumulation and MTH1 expression. These results suggest that undifferentiated brain tumors such as highgrade glioma and medulloblastoma are exposed to more oxidative stress than are differentiated brain tumors.

\section{Acknowledgments}

We thank Ms. Kazue Hatanaka for her excellent technical assistance and Ms. Katherine Ono for reviewing the manuscript. 


\section{References}

Akiyama, M., Maki, H., Sekiguchi, M., and Horiuchi T. (1989) A specific role of MutT protein: To prevent dG.dA mispairing in DNA replication. Proc. Natl. Acad. Sci. U.S.A. 86, 3949-3952.

Bestwick, R.K., Moffett, G.L., and Mathews, C.K. (1982) Selective expansion of mitochondrial nucleoside triphosphate pools in antimetabolite-treated HeLa cells. J. Biol. Chem. 257, 9300-9304.

Boiteux, S., and Radicella, J.P. (1999) Base excision repair of 8-hydroxyguanine protects DNA from endogenous oxidative stress. Biochimie 81, 59-67.

Cobbs, C.S., Brenman, J.E., Aldape, K.D., Bredt, D.S., and Israel, M.A. (1995) Expression of nitric oxide synthase in human central nervous system tumors. Cancer Res. 55, 727-730.

Floyd, R.A. (1990) The role of 8-hydroxyguanine in carcinogenesis. Carcinogenesis 11, 1447-1450.

Fraga, C.G., Shigenaga, M.K., Park, J.W., Degan, P., and Ames, B.N. (1990) Oxidative damage to DNA during aging: 8-Hydroxy-2'-deoxyguanosine in rat organ DNA and urine. Proc. Natl. Acad. Sci. U.S.A. 87, 4533-4537.

Fujikawa, K., Kamiya, H., Yakushiji, H., Fujii, Y., Nakabeppu, Y., and Kasai, H. (1999) The oxidized forms of dATP are substrates for the human MutT homologue, the hMTH1 protein. J. Biol. Chem. 274, 18201-18205.

Furuichi, M., Yoshida, M.C., Oda, H., Tajiri, T., Nakabeppu, Y., Tsuzuki, T., and Sekiguchi, M. (1994) Genomic structure and chromosome location of the human mutT homologue gene MTH1 encoding 8-oxo-dG TPase for prevention of $A: T$ to $C: G$ transversion. Genomics 24, 485-490.

Inoue, M., Osaki, T., Noguchi, M., Hirohashi, S., Yasumoto, K., and Kasai, H. (1998) Lung cancer patients have increased 8-hydroxydeoxyguanosine levels in peripheral lung tissue DNA. Jpn. J. Cancer Res. 89, 691-695.

Kakuma, T., Nishida, J., Tsuzuki, T., and Sekiguchi, M. (1995) Mouse MTH1 protein with 8-oxo-7,8-dihydro-2'-deoxyguanosine 5'-triphosphatase activity that prevents transversion mutation: CDNA cloning and tissue distribution. J. Biol. Chem. 270, 25942-25948.

Kang, D., Nishida, J., lyama, A., Nakabeppu, Y., Furuichi, M., Fujiwara, T., Sekiguchi, M., and Takeshige, K. (1995) Intracellular localization of 8-oxodG TPase in human cells, with special reference to the role of the enzyme in mitochondria. J. Biol. Chem. 270, 14659-14665.

Kennedy, C.H., Cueto, R., Belinsky, S.A., Lechner, J.F., and Pryor, W.A. (1998) Overexpression of hMTH1 mRNA: A molecular marker of oxidative stress in lung cancer cells. FEBS Lett. 429, 17-20.

Kondo, S., Toyokuni, S., Iwasa, Y., Tanaka, T., Onodera, H., Hiai, H., and Imamura, M. (1999) Persistent oxidative stress in human colorectal carcinoma, but not in adenoma. Free Radic. Biol. Med. 27, 401-410.

Lee, B.M., Jang, J.J., and Kim, H.S. (1998) Benzo[a]pyrene diol-epoxide-I-DNA and oxidative DNA adducts associated with gastric adenocarcinoma. Cancer Lett. 125, 61-68.

Maki, H., and Sekiguchi, M. (1992) MutT protein specifically hydrolyses a potent mutagenic substrate for DNA synthesis. Nature 355, 273-275.

Matsui, M., Nishigori, C., Toyokuni, S., Takada, J., Akaboshi, M., Ishikawa, M., Imamura, S., and Miyachi, Y. (1999) The role of oxidative DNA damage in human arsenic carcinogenesis: Detection of 8-hydroxy-2'-deoxyguanosine in arsenic-related Bowen's disease. J. Invest. Dermatol. 113, 26-31.

Michaels, M.L., Cruz, C., Grollman, A.P., and Miller, J.H. (1992) Evidence that MutY and MutM combine to prevent mutations by an oxidatively damaged form of guanine in DNA. Proc. Natl. Acad. Sci. U.S.A. 89, 7022-7025.

Musarrat, J., Arezina-Wilson, J., and Wani, A.A. (1996) Prognostic and aetiological relevance of 8-hydroxyguanosine in human breast carcinogenesis. Eur. J. Cancer 32A, 1209-1214.

Nishioka, K., Ohtsubo, T., Oda, H., Fujiwara, T., Kang, D., Sugimachi, K., and Nakabeppu, Y. (1999). Expression and differential intracellular localization of two major forms of human 8-oxoguanine DNA glycosylase encoded by alternatively spliced OGG1 mRNAs. Mol. Biol. Cell 10, 1637-1652.
Nowak, S., Zukiel, R., Olsen, A., Siboska, G., Gawronska I., and Barciszewski, J. (1999). 8-Oxo-guanosine as a marker of neoplastic process in brain. Neurol. Neurochir. Pol. 33, 1339-1348.

Oda, H., Nakabeppu, Y., Furuichi, M., and Sekiguchi, M. (1997). Regulation of expression of the human MTH1 gene encoding 8-oxo-dGTPase: Alternative splicing of transcription products. J. Biol. Chem. 272, 17843-17850.

Oda, H., Taketomi, A., Maruyama, R., Itoh, R., Nishioka, K., Yakushiji, H., Suzuki, T., Sekiguchi, M., and Nakabeppu, Y. (1999). Multi-forms of human MTH1 polypeptides produced by alternative translation initiation and single nucleotide polymorphism. Nucleic Acids Res. 27, 4335-4343.

Ohtsubo, T., Nishioka, K., Imaiso, Y., Iwai, S., Shimokawa, H., Oda, H., Fujiwara, T., and Nakabeppu, Y. (2000) Identification of human MutY homolog (hMYH) as a repair enzyme for 2-hydroxyadenine in DNA and detection of multiple forms of hMYH located in nuclei and mitochondria. Nucleic Acids Res. 28, 1355-1364.

Okamoto, K., Toyokuni, S., Uchida, K., Ogawa, O., Takenewa, J., Kakehi, Y., Kinoshita, H., Hattori-Nakakuki, Y., Hiai, H., and Yoshida, O. (1994) Formation of 8-hydroxy-2'-deoxyguanosine and 4-hydroxy-2-nonenal-modified proteins in human renal-cell carcinoma. Int. J. Cancer 58, 825-829.

Okamoto, K., Toyokuni, S., Kim, W.J., Ogawa, O., Kakehi, Y., Arao, S., Hiai H., and Yoshida, O. (1996) Overexpression of human mutT homologue gene messenger RNA in renal-cell carcinoma: Evidence of persistent oxidative stress in cancer. Int. J. Cancer 65, 437-441.

Olinski, R., Zastawny, T., Budzbon, J., Skokowski, J., Zegarski, W., and Dizdaroglu, M. (1992) DNA base modifications in chromatin of human cancerous tissues. FEBS Lett. 309, 193-198.

Oliva, M.R., Ripoll, F., Muniz, P., Iradi, A., Trullenque, R., Valls, V., Drehmer, E., and Saez, G.T. (1997) Genetic alterations and oxidative metabolism in sporadic colorectal tumors from a Spanish community. Mol. Carcinog. 18, 232-243.

Sakumi, K., Furuichi, M., Tsuzuki, T., Kakuma, T., Kawabata, S., Maki, H., and Sekiguchi, M. (1993) Cloning and expression of cDNA for human enzyme that hydrolyzes 8-oxo-dGTP, a mutagenic substrate for DNA synthesis. J. Biol. Chem. 268, 23524-23530.

Sekiguchi, M. (1996) MutT-related error avoidance mechanism for DNA synthesis. Genes Cells 1, 139-145.

Shimura-Miura, H., Hattori, N., Kang, D., Miyako, K., Nakabeppu, Y., and Mizuno, Y. (1999) Increased 8-oxo-dG TPase in the mitochondria of substantia nigral neurons in Parkinson's disease. Ann. Neurol. 46, 920-924.

Slupska, M.M., Baikalov, C., Luther, W.M., Chiang, J.-H., Wei, Y.-F., and Miller, J.H. (1996) Cloning and sequencing a human homolog $(h M Y H)$ of the Escherichia coli mutY gene whose function is required for the repair of oxidative DNA damage. J. Bacteriol. 178, 3885-3892.

Slupska, M.M., Luther, W.M., Chiang, J.-H., Yang, H., and Miller, J.H. (1999) Functional expression of $\mathrm{hMYH}$, a human homolog of the Escherichia coli MutY protein. J. Bacteriol. 181, 6210-6213.

Tajiri, T., Maki, H., and Sekiguchi, M. (1995) Functional cooperation of MutT, MutM and MutY proteins in preventing mutations caused by spontaneous oxidation of guanine nucleotide in Escherichia coli. Mutat. Res. 336, 257267.

Tanaka, H., Arakawa, H., Yamaguchi, T., Shiraishi, K., Fukuda, S., Matsui, K., Takei, Y., and Nakamura, Y. (2000) A ribonucleotide reductase gene involved in a p53-dependent cell-cycle checkpoint for DNA damage. Nature 404, 42-49.

Tchou, J., Kasai, H., Shibutani, S., Chung, M.H., Laval, J., Grollman, A.P., and Nishimura, S. (1991) 8-oxo-guanine (8-hydroxyguanine) DNA glycosylase and its substrate specificity. Proc. Natl. Acad. Sci. U.S.A. 88, 4690-4694.

Toyokuni, S., Okamoto, K., Yodoi, J., and Hiai, H. (1995) Persistent oxidative stress in cancer. FEBS Lett. 358, 1-3. 
Toyokuni, S., Tanaka, T., Hattori, Y., Nishiyama, Y., Yoshida, A., Uchida, K., Hiai, H., Ochi, H., and Osawa, T. (1997) Quantitative immunohistochemical determination of 8-hydroxy-2'- deoxyguanosine by a monoclonal antibody N45.1: Its application to ferric nitrilotriacetate-induced renal carcinogenesis model. Lab. Invest. 76, 365-374.

Wani, G., Milo, G.E., and D'Ambrosio, S.M. (1998) Enhanced expression of the 8-oxo-7,8-dihydrodeoxyguanosine triphosphatase gene in human breast tumor cells. Cancer Lett. 125, 123-130.

Yakushiji, H., Maraboeuf, F., Takahashi, M., Deng, Z.-S., Kawabata, S.,
Nakabbeppu, Y., and Sekiguchi, M. (1997) Biochemical and physicochemical characterization of normal and variant forms of human MTH1 protein with antimutagenic activity. Mutat. Res. 384, 181-194.

Yamamoto, T., Hosokawa, K., Tamura, T., Kanno, H., Urabe, M., and Honjo, H. (1996) Urinary 8-hydroxy-2'-deoxyguanosine (8-OHdG) levels in women with or without gynecologic cancer. J. Obstet. Gynecol. Res. 22, 359-363.

Yoshii, Y., Saito, A., Zhao, D.W., and Nose, T. (1999) Copper/zinc superoxide dismutase, nuclear DNA content, and progression in human gliomas. J. Neurooncol. 42, 103-108. 